\title{
A Proposal for Palliative Care of Acute Patients with Covid-19 in the Hospital
}

\author{
ANTONIO JOSE Pita Carranz ${ }^{1}$, MARIA JULIA Fernandez Bueno ${ }^{1}$ and MERCEDES Vinuesa \\ Sebastian $^{2 *}$ \\ ${ }^{1}$ Unit of Palliative Care. Universitary Hospital of the Princess, England \\ ${ }^{2}$ Coordinadora de Calidad, Servicio de M Preventiva, Hospital Universitario de La Princesa, Unit of Quality Care. Universitary Hospital of \\ the Princess, England \\ *Corresponding author: MERCEDES Vinuesa Sebastian, Coordinadora de Calidad, Servicio de M Preventiva, Hospital Universitario \\ de La Princesa, Unit of Quality Care. Universitary Hospital of the Princess, England
}

\begin{tabular}{l} 
ARTICLE INFO \\
\hline Received: February 23, 2021 \\
Published: March 05, 2021 \\
\hline Citation: ANTONIO JOSE Pita C, MARIA \\
JULIA Fernandez B, MERCEDES Vinuesa \\
S. Protocol for Generating Cell Lines Spe- \\
cific to Patients with Duchenne Muscular \\
Dystrophy and Able to Induce Pluripotent \\
Stem Cells. Biomed J Sci \& Tech Res 34(3)- \\
2021. BJSTR. MS.ID.005546.
\end{tabular}

ABSTRACT

Keywords: Palliative Care; Covid; Pandemic; Hospital

\section{Short Communication}

In WHO's $67^{\text {th }}$ World Health Assembly (2014), resolution WHA67.19 was published with the title "Strengthening of palliative care as component of comprehensive care throughout the life course". Always under scientific criteria, palliative care (PC) should be included in country's healthcare systems for every disease group and level of assistance. After SARS-CoV-2 international emergence, we started to provide health care for an increasing number of patients suffering from COVID-19, facing high levels of disease burden and mortality. Even if there's no explicit mention to specific PC in WHO's recommendations to treat COVID-19, we understood it as an ethical imperative to provide high quality PC to every patient who will likely die of COVID-19 [1]. Providing PC during the pandemic requires not only a deep conviction from the health personnel but also a strategy to guarantee every patient receives the adequate care. Due to the organizational needs and the complex implementation, making PC (including end of life care) safe and efficient poses a critical and difficult challenge [2]. Patients condition deteriorates swiftly, health professionals are overloaded and family members are recommended to isolate (no contact, no presence in the same room) themselves from their relatives and beloved ones. The pandemic has brought a severe health, social and financial crisis, pushing the limits of the health care systems without clearly knowing for how long it will last. A pandemic can unleash or amplify suffering on multiple levels: death, physical and mental conditions, but also financial or social distress. If we, as health professionals, are able minimize or avoid hardship, we will have set some response mechanisms in motion [3].

I. With respect to the response of a Hospital, we have considered three items:
a. What is our objective?
b. What is the situation?
c. What can we do?
II. What is our objective?
a. Safety and quality in PC to every patient in need for it 
b. Family care

c. Support for the health professional

We need to identify those patients who need PC (triage), to prepare the treatment as soon as possible with safety and efficiency (resources: bed management, trained professionals, drugs, devices), to stablish relationships with the patient and the family and finally, with special relevance, facilitate the connection between patient and family.

III. What is the situation?

a. Saturated hospital (emergency, intensive care unit, hospital beds) with patients who require a high level of assistance (mostly COVID patients)

b. Growing number of patients arriving, mostly with COVID.

c. Experienced health professionals, who participate in the organization of the health care.

d. Health professionals exposed to the risk of disease, which impacts the type of health care.

e. Families going through an unprecedented situation, facing pain and suffering, not being able to touch (use of individual protection equipment), assist or provide moral support to their relatives

We have our usual facilities and some extra specially arranged for the pandemic (inside and outside the hospitals), in which it's possible to offer care more efficiently and safely, both for the patients and the health professionals. The increasing number of patients arriving to the hospital adds another challenge: to facilitate the communication between family and patient which should, as far as possible, assist and alleviate the suffering. The pandemic is severely stressing healthcare systems and hence the institutions. Financial capacity is limited and so is the number of experienced professionals and, therefore, an adequate management of resources is a must for each institution.

\section{What can we do?}

This is the key that we are looking for and will hopefully answer the question: "how are we going to integrate PC in the hospital for every patient that needs it during the COVID pandemic?"

\section{Objectives}

To stablish principles that allow to evaluate the efficiency, safety and quality of the PC for the patients who need it during the COVID pandemic.

\section{Patients and Methods}

A consensual proposal, based on literature review, resource availability, patient in need of PC forecasting and analysis and opinion of experts from several domains (acute care, hospitalization, and PC), has been elaborated.
The scope of our analysis is the Hospital, and, for that reason, we have intentionally not involved other levels of care (which, on the other hand, it would have been possible to). PC professionals belonging to the Palliative Care Support Team (PCST) are the focal point of interconnection with external PC experts. Regarding the patients, our target is to provide PC for everyone (COVID and non COVID) in need of it. Two care proposals for the PCST have been elaborated and analyzed together with the rest of the team responsible for the care of COVID patients in the hospital. On one hand, PC physician in charge of the patients; on the other, as PC consultant for the physician in charge of the patient. Given the aforementioned factors, we opted for the later approach, the consultant professional, stablishing procedures for work and follow-up.

\section{Process}

Several activities are considered throughout the whole care process. Whilst saving lives is the ruling principle for admitted patients, alleviating suffering has become a crucial point in the response to COVID, which should be agile and come from every involved physician (regardless they are PC specialists or not). Hereafter, the parts of the process are briefly commentated. The first stage of the process is the triage of the patients. The already complex decision in the classification of patients, is further increased by other factors like communication with family, safety and efficiency of the care, end of life care, hardship while supporting the patient, isolation measures, exhaustion, and psychological stress. Is for those reasons that such decision should never be taken by a single person but to be discussed by a multidisciplinary team of physicians with experts in, for example, intensive care, internal medicine, and PC [4]. The psychological burden resulting of the triage is diverse (patient and family will feel abandoned, moral distress on the professionals involved) and should be done early. Consequently, it is essential to count with qualified psychological, social and spiritual support. The pandemic has pushed us to focus on the necessity of integrating public health, clinic medicine and PC on every possible level, highlighting the importance of the human connection in the scope of an advanced disease [5]. Proportionality and adequacy criteria should be complemented, as some authors say, with equality, utility and, as we believe, feasibility. Given the scarce resources, the allocation should be adequate with regards to ethics and public health principles [6].

I. Amongst the key items in the process, recurrently covered in the literature [7-9], are found the following ones:

a. Control of pain and other symptoms.

b. Shared decision making (medical team, patient, and family).

c. Communication skills, which make possible reduce the distress when announcing bad news and help to take complex decisions. 


\section{d. Provide care during the grief (it can be complex).}

Those patients (with or without COVID) who can profit from PC are selected and evaluated by the multidisciplinary team. If the evaluation has a positive outcome, the PCST takes over as consultant for the responsible physician on the comprehensive treatment and family care. In a study performed by a unit of critical patients in New York [10], patients receiving PC were older, sicker, and needed more frequently mechanic ventilation. On the contrary, patients who died and did not receive PC were younger and required noninvasive ventilation support. Our proposal to manage PC had two clear advantages like decision-making is shared by several physicians (in a context of great uncertainty, scarce resources, and quick evolution), and it is possible to cover more patients by the PCST despite its limited workforce. Response guides have been elaborated and an active support regarding their application has been offered continuously, even if they were not registered in the internal information system. However, it has two disadvantages, the recruitment of new patients depends in all cases on the call of other doctors and there is a different level of knowledge among the nursing staff of the different hospitalization units, involved in the treatment and follow-up of patients.

Nevertheless, in 2020, 598 interventions have been performed, of which 463 were on hospitalized patients. The reasons to consult with the PCST have been diverse and only 1,5\% of the cases were related to, exclusively, a COVID patient. This approach has allowed for having a wide presence in patient care and, at the same time, for being consultants on several aspects within the same patient. It also provided a way not to stop the PC when the professionals within the PCST developed the disease, even if they were not directly involved in most of the complex decisions impacting patients. However, 598 direct interventions were performed in 2020, of which 463 were on hospitalized patients. The reasons to consult with the PCST have been diverse, aspects of patient management, family care, grief, management of different symptoms or drug interactions. This proposal has allowed for having a wide presence in patient care and, at the same time, for being consultants one or several aspects within the same patient.

It also provided a way not to stop the PC when professionals within the PCST developed the disease. In the study by Julia-Torras, et al [11], the core competences and constituents in PC according to the European Association of Palliative Care are analyzed, specific proposals when facing with new outbreaks of COVID-19 or related diseases in reference to competencies in PC. It's also highlighted the relevance of stablishing a properly trained team, the triage of patients needing PC (identification of end-of-life situation, symptom control, emotional, social and spiritual support) and the necessary skills to communicate bad news. The specific approach to deal with COVID and its fast evolution, it's recommended to involve PC professionals in the teams who directly treat these patients. In our experience, this approach is the most efficient, although further evaluation is needed to improve the availability of resources.

\section{Conclusion}

\section{PC are an Essential Part of COVID-19 Response}

The adaptation of the PC during the COVID pandemic provides a response to characteristics of the disease and the impact on healthcare system and society. Such challenge affects every level of care, health institutions, healthcare professionals, patients and family, also from the financial perspective. In this highly mutable environment, a multidisciplinary approach reaching every patient in need of it seems to be adequate. It's been manifested the prominent importance of providing emotional support to patients and caregivers, the necessity to form workgroups and to keep an agile and flexible organization in the healthcare. The benefits from this change and the eventual progress in healthcare depends on our capacity to carry out its implementation in our entities. The COVID pandemic has boosted the value of $\mathrm{PC}$ and the requirement to reorganize ourselves according to technical criteria, with experienced professionals. But is also necessary taking into account the specific environment and the availability of resources, scarce on which we should reflect and consider taking action to increment them.

\section{Funding}

This original paper has not received funding of any kind.

\section{Acknowledgement}

To all the professionals of the University Hospital of the Princess, for their work and dedication during the COVID-19 pandemic.

\section{References}

1. (2020) Word Health Organization. Maintaining essential health services: operational guidance for the COVID-19 context, WHO.

2. Lukas R, Felicia MK, Liliana De Lina, Cornelia De Joncheere, Afsan B (2020) The key role of palliative care in response to the COVID-19 tsunami of suffering. Lancet 395: 1467-1469.

3. Etkind SN, Bone AE, Lovell N, Cripps RL, Harding R, et al. (2020) The Role and Response of Palliative Care and Hospice Services in Epidemics and Pandemics: A Rapid Review to Inform Practice During the COVID-19 Pandemic. Journal of Pain and Symptom Management 60(1): e31-e40.

4. Riva L, Caraceni A, Vigorita F, Berti J, Martinelli MP, et al. (2020) COVID-19 emergency and palliative medicine: an intervention model. BMJ Supportive \& Palliative Care 0: 1-4.

5. Rodin G, Zimmermann C, Rodin D, Al Awamer A, Sullivan R, et al. (2020) COVID-19, palliative care and public health. European Journal of Cancer 136: 95-98.

6. Wallace CL, Wladkowski SP, Gibson A, White P (2020) Grief During the COVID-19 Pandemic: Considerations for Palliative Care providers. Journal of Pain and Symptom Management 60(1): e70-e76.

7. Chidiac C, Feuer D, Naismith J, Flatley M, Preston N (2020) Emergency Palliative care Planning and Support in a COVID-19 Pandemic. Journal of Palliative Medicine 23(6): 752-753. 
8. Heath L, Yates S, Carey M, Miller M (2020) Palliative Care During COVID-19: Data and Visits From Loved Ones. American Journal of Hospice \& Palliative Medicine 37(11): 988-991.

9. Janssen DJA, Ekström M, Currow DC, Johnson MJ, Maddocks M, et al. (2020) COVID-19:guidance on palliative care from European Respiratory Society international task force. European Respiratory Journal 56: 2002583.

\section{ISSN: 2574-1241}

DOI: 10.26717/BJSTR.2021.34.005546

MERCEDES Vinuesa Sebastian. Biomed J Sci \& Tech Res

This work is licensed under Creative Commons Attribution 4.0 License

Submission Link: https://biomedres.us/submit-manuscript.php
10. Sheehan J, Sing Ho K, Poon J, Sarosky K, Fung JY (2020) Palliative care in critically ill COVID-19 patients: the early New York City experience. BMJ Supportive \& Palliative Care p. 1-5.

11. Julià J, De Iriarte N, Porta J (2020) COVID-19: Quick reflections from palliative care before the next epidemic. Med Clin 156: 29-32.

$\begin{array}{ll}\text { BIOMEDICAL } & \text { Assets of Publishing with us } \\ \text { RESEARCHES } & \text { - Global archiving of articles } \\ \text { - Immediate, unrestricted online access }\end{array}$

